\title{
A virada jurisprudencial na exigência de lei complementar para a instituição de tributos: uma abordagem a partir do pensamento de Ronald Dworkin
}

\author{
The jurisprudential turn in the requirement of a lei complementar for the \\ institution of taxes: an approach from Ronald Dworkin's thought
}

(D) Carlos Gustavo Chada Chaves

Mestrando em Direito, Políticas Públicas e Desenvolvimento Regional - CESUPA Juiz Federal Substituto do Tribunal Regional Federal da $1^{\mathrm{a}}$ Região

carloschaves1980@uol.com.br

Jean Carlos Dias

Doutor em Direitos Fundamentais e Relações Sociais - UFPA Professor de Teoria do Direito, Direito Processual Civil, Teoria Geral do Processo e Direito Econômico nos cursos de graduação e pós-graduação do CESUPA, onde também coordena o programa de pós-graduação em Direito jeandias@cesupa.br

Resumo: Dworkin, partindo da ideia de que o Direito é o produto da interpretação da prática jurídica, desenvolve a concepção de direito como integridade. O presente artigo, portanto, tem os seguintes objetos: traçar considerações da concepção Dworkiniana de Direito como integridade e sua aplicação aos chamados casos difíceis; e testar se a jurisprudência firmada no agravo regimental em recurso extraordinário $\mathrm{n}^{\circ}$ 917.950/SP respeitou a concepção de Direito como integridade, defendida por Dworkin. O referencial teórico será "O Império do Direito". O método a ser utilizado no presente trabalho será o dedutivo. A pesquisa será pautada em bibliografia nacional e estrangeira e na jurisprudência do Supremo Tribunal Federal.

Palavras- chave: Dworkin; Direito como integridade; romance em cadeia; jurisprudência do Supremo Tribunal Federal; agravo regimental em recurso extraordinário nº 917.950/SP.

Abstract: Dworkin, starting from the idea that law is the product of the interpretation of legal practice, develops the concept of Law as integrity. The present article, therefore, has the following objects: to outline considerations of the Dworkinian conception of Law as integrity and its application to the so-called difficult cases; and to test whether the jurisprudence established in the appeal in extraordinary appeal No. 917.950 / SP respected the concept of Law as integrity, defended by Dworkin. The theoretical framework will be "The Empire of Law". The method to be used in the present work will be the deductive one. The research will be based on national and foreign bibliography and the jurisprudence of the Supremo Tribunal Federal.

Keywords: Dworkin; Right as integrity; chain novel; jurisprudence of Supremo Tribunal Federal; agravo regimental em recurso extraordinário no 917.950/SP. 
CHAVES, Carlos Gustavo Chada; DIAS, Jean Carlos. A virada jurisprudencial na exigência de lei complementar para a instituição de tributos: uma abordagem a partir do pensamento de Ronald

Dworkin

Para citar este artigo

ABNT NBR 6023:2018

CHAVES, Carlos Gustavo Chada; DIAS, Jean Carlos. A virada jurisprudencial na exigência de lei complementar para a instituição de tributos: uma abordagem a partir do pensamento de Ronald Dworkin. Prisma Jurídico, São Paulo, v. 20, n. 2, p. 195-215, jul./dez. 2021. http://doi.org/10.5585/prismaj.v20n2.17438.

\section{Introdução}

O comportamento de qualquer indivíduo que se encontra sob a égide de um sistema jurídico (pelo menos é isso que dele se espera) se baseia e é limitado pelos padrões vigentes: firmam-se compromissos contratuais, abrem-se empresas, avaliam-se os riscos de determinados negócios etc. sempre na expectativa de que seus atos (e dos próprios agentes públicos) estão regulamentados por determinados padrões, que lhes garantam agir dentro de um âmbito mínimo de previsibilidade.

Assim, a jurisprudência do Supremo Tribunal Federal era no sentido de que a própria validade da lei local, tributária ou não, quando exigida constitucionalmente, estava condicionada à edição de lei complementar nacional. Diversas leis locais que instituíram tributos e/ou que criaram municípios tiveram a sua inconstitucionalidade reconhecida, em razão de inexistência de prévia lei complementar nacional autorizadora, sendo declaradas, portanto, nulas.

É neste sentido que o presente texto demonstrará que a guinada jurisprudencial firmada no âmbito do Agravo Regimental em Recurso Extraordinário no 917.950/SP, onde se reconheceu a validade da lei paulista $\mathrm{n}^{\mathrm{o}}$ 11.001/01 autorizativa de cobrança de ICMS de pessoa física, mesmo sendo anterior a vigência da LC federal 114/02, vai de encontro à concepção de Direito como integridade defendida por Dworkin.

O presente estudo, portanto, apresentará ideias centrais da concepção Dworkiniana de Direito como integridade, como aquela que melhor justifica a coerção estatal principalmente nos chamados "casos difíceis", ou seja, aqueles onde inexistem padrões normativos ou políticos anteriores. Posteriormente, será feita uma análise, a partir de julgamentos proferidos pelo Supremo Tribunal Federal, donde se demonstrará que a jurisprudência de nossa Corte Superior firmada no Agravo Regimental em Recurso Extraordinário n ${ }^{\circ}$ 917.950/SP não se adéqua à concepção de Direito como integridade.

Para tanto, o presente trabalho será dividido da seguinte forma: no primeiro capítulo serão apresentados o modelo interpretativo de Dworkin, o conceito de Direito para Dworkin e sua concepção como integridade; no segundo, serão apresentados julgamentos emblemáticos 
do Supremo Tribunal Federal, os quais tiveram como pano de fundo o mesmo tema, qual seja a nulidade (ou não) de leis locais, diante da inexistência de lei complementar nacional exigida pela Constituição Federal como estabelecedora de normativo geral. Em seguida, no capítulo terceiro, será feita análise específica do entendimento firmado no Agravo Regimental em Recurso Extraordinário no 917.950/SP, para em seguida, refutá-lo com base na Teoria do Direito como integridade Dworkiniano.

\title{
1 Direito como integridade
}

Dworkin apreende o direito como um conceito interpretativo (2007, p. 488). O Direito não é apenas um sistema de normas, mas "uma complexa teia de articulações de prática de autoridade, legitimação e argumentação" (MACEDO JÚNIOR, 2013, p. 210),

Dworkin, já na parte final de sua obra (2007, p. 492) assim sintetiza o conceito de Direito:

\begin{abstract}
É uma atitude interpretativa e auto-reflexiva, dirigida à política no mais amplo sentido. É uma atitude contestadora que torna todo o cidadão responsável por imaginar quais são os compromissos públicos de uma sociedade com os princípios, e o que tais compromissos exigem em cada circunstância. O caráter contestador do direito é confirmado, assim como é reconhecido o papel criativo das decisões privadas, pela retrospectiva da natureza judiciosa das decisões tomadas pelos tribunais e também pelo pressuposto regulador de que, ainda que os juízes devam ter a última palavra, sua palavra não será a melhor por essa razão. A atitude do direito é construtiva: sua finalidade, no espírito interpretativo, é colocar o princípio acima da prática para mostrar o melhor caminho para um futuro melhor, mantendo a boa-fé com relação ao passado. É, por último, uma atitude fraterna, uma expressão de como somos unidos pela comunidade apesar de divididos por nossos projetos, interesses e convicções.
\end{abstract}

As proposições jurídicas que irão nortear a regulação do meio social não se limitam assim a uma análise meramente descritiva (normas), como entendem os positivistas, pois o Direito é a prática de interpretação da "história jurídica, que combina elementos tanto da descrição quanto da valoração, sendo porém diferente de ambas” (DWORKIN, 2001, p. 219).

Dworkin vai equiparar a prática interpretativa do Direito ao exercício literário em construção. Para tanto, desenvolve a ideia de um "romance em cadeia" (chain novel), "na medida em que se exige do juiz, como um romancista na corrente, uma interpretação jurídica de caráter construtivo que dê sequência à história da prática social do Direito" (VIANA, 2015, p. 60$)^{1}$.

\footnotetext{
1 "Dworkin then proceeds, along grounds he has made familiar in recent years, to analogize the development of the law to the writing of a chain novel. Each succeeding author is obliged to search for the interpretation of the text supplied to him that best fits that text" (CHRISTIE, 1987, p. 173)
} 
CHAVES, Carlos Gustavo Chada; DIAS, Jean Carlos. A virada jurisprudencial na exigência de lei complementar para a instituição de tributos: uma abordagem a partir do pensamento de Ronald

Os juízes nesta atividade interpretativa, ao mesmo tempo em que ficam vinculados à "parte do romance" produzida pelos autores responsáveis pelas etapas anteriores, no processo criativo, interpretam aquilo que já foi feito, dando continuidade, agora com novos elementos, ao romance.

O dever do juiz, neste processo interpretativo é, portanto, compreender aquilo que já fora feito nas etapas anteriores e dar sequência à história, e não "inventar" algo novo sem vínculo com aquilo que já fora argumentado. É, da mesma forma que a obrigação judicial, de responsabilidade do autor subsequente do romance escrever algo que esteja de acordo com o primeiro capítulo e acrescentar material novo (MORRINSON, 2006, p. 518).

Deve adotar um ponto de vista sobre o romance que vai se formando ao poucos, alguma teoria que lhe permita trabalhar elementos como personagens, trama, gênero, tema e objetivo, para decidir o que considerar como continuidade e não como novo começo (DWORKIN, 2007, p. 277).

O juiz, portanto, no enredo deste "romance em cadeia", não possui liberdade criativa ampla, mas compromissos em duas dimensões: dimensão da adequação e dimensão de ajuste à melhor leitura possível da obra em desenvolvimento, depois de considerados todos os seus aspectos.

Quanto à dimensão da adequação, “deve-se identificar quais interpretações são compatíveis com os capítulos anteriores. Essas interpretações devem ser capazes de explicar o texto de forma substancial" (OLIVEIRA, 2016). Em que pese inexistir necessidade de que sua interpretação deva ser absolutamente ajustada a todos os elementos integrantes do texto, não pode ser criativa ao ponto de ignorar os elementos centrais daquilo que já fora escrito por outros autores. "Será mal sucedida se deixar sem explicação algum importante aspecto estrutural do texto, uma trama secundária tratada como se tivesse grande importância dramática, ou uma metáfora dominante recorrente" (DWORKIN, 2007, p. 277) ${ }^{2}$.

Quanto à segunda dimensão, refere-se à possibilidade da existência de mais de uma hipótese de interpretação ao conjunto do texto. Neste caso, deve o juiz, aqui visto como coautor do romance em cadeia, julgar "qual dessas leituras possíveis se ajusta melhor à obra em desenvolvimento, depois de considerados todos os aspectos em questão" (DWORKIN, 2007,

\footnotetext{
${ }^{2}$ When one argues the truth of a proposition of law, the argument presumes that the story of the proposition fits the existential facts of the history of political coercion (the dimension, axis, or measure of fit) and that the proposition does honor to history by putting it in the best light possible, all things considered (the dimension, axis, or measure of honor). Put in terms of legal practice, one must ask, "does the proposition fit the constitution, statutes, and cases, and does the proposition honor the political values of justice, fairness, and due process?" Integrity is the motivating force for the location of the focal point (SNOWDEN, 1991, p. 52-53)
} 
CHA VES, Carlos Gustavo Chada; DIAS, Jean Carlos. A virada jurisprudenciall na exigência de lei complementar para a instituição de tributos: uma abordagem a partir do pensamento de Ronald

Dworkin

p. 277). Neste processo, o juiz canaliza seus esforços para decifrar, em algum conjunto coerente de princípios, a melhor interpretação da estrutura política e da doutrina da sua comunidade. Após, identificam-se quais interpretações são adequadas a esse conjunto de princípios, sendo que, somente se houver mais de uma interpretação possível, identifica-se a que maximize esse conjunto coerente de princípios. "O direito como integridade será determinante tanto na adequação quanto na justificação do melhor significado" (OLIVEIRA, 2016).

Adverte, todavia, Sadowski (2001, p. 1108-1109)

\begin{abstract}
However, often in law it is not just the interpretation of the same cases that is at issue, but it is the very question of which cases and which issues are at issue. Thus, there are two main areas at stake: 1) identifying the "appropriate" precedent; and 2) interpreting the precedent or appropriate legal tradition. Unlike Dworkin's chain novel, judicial decisions are not neatly collected and organized within an intact single cover, and thus it is not always obvious which earlier "chapters" are relevant. Often in law, it is not clear what the issue is; in fact, what judges and readers perceive as the issue itself is an act of interpretation, which depends on the various assumptions that different readers bring to the same problem and legal text. Even judges responding to the same set of briefs do not always agree on what the issues are.
\end{abstract}

Dworkin (2007, p. 113) entende que nenhum Direito pode florescer como empreendimento interpretativo sem que exista, dentro do seio da comunidade, certo consenso inicial sobre quais práticas são jurídicas ${ }^{3}$.

Para tanto identificará culturalmente as seguintes práticas tidas como jurídicas: legislaturas, tribunais, decisões tomadas nas agências e organismos administrativos e, nos Estados Unidos da América, também a Constituição. Este seria, portanto, o ponto de partida em certo consenso para se discutir qualquer forma de concepção interpretativa do direito.

Segundo Viana (2015, p. 65), Dworkin faz uso frequente da distinção entre conceitos e concepções para demonstrar que, em
diferentes graus de abstração, os juristas divergem acerca do conteúdo e do modo de
interpretar o direito, de sorte a refletir certo acordo inicial de um conjunto distinto de
ideias (conceito), cuja controvérsia latente é identificada e assumida, quando da
exposição de concepções rivais desse conceito.

\footnotetext{
3 "In Dworkin's model, there are three stages to the practice of constructive interpretation. First, in the "preinterpretive" stage, "the rules and standards [are] taken to provide the tentative content of the practice. . . identified." Second, in the "interpretive" stage, "the interpreter settles on some general justification for the main elements of the practice identified at the preinterpretive stage. Third, in the "postinterpretive" stage, "[the judge] adjusts his sense of what the practice 'really' requires so as better to serve the justification he accepts at the interpretive stage."' In other words, at the preinterpretive stage the judge identifies the "paradigms" of the relevant legal practice; at the interpretive stage the judge decides which scheme of principles best fits current legal practice and the judge's conception of political morality; and at the postinterpretive stage the judge must add to or subtract from the current conception of legal practice given the demands made by the morally best scheme of principles" (Dorkin, 1998, p. 1091-1092).
} 
CHAVES, Carlos Gustavo Chada; DIAS, Jean Carlos. A virada jurisprudencial na exigência de lei complementar para a instituição de tributos: uma abordagem a partir do pensamento de Ronald

Dworkin

Quanto às concepções, consistiriam no aprimoramento da interpretação inicial e consensual (conceito de Direito), tendo como função o oferecimento de respostas às seguintes perguntas colocadas pelo conceito:

\begin{abstract}
Justifica-se o suposto elo entre o direito e coerção? Faz algum sentido exigir que a força pública seja usada somente em conformidade com os direitos e responsabilidade que decorrem de decisões políticas anteriores? Segundo, se tal sentido existe, qual é ele? Terceiro, que leitura de decorrer - que noção de coerência com decisões precedentes - é a mais apropriada? (Dworkin, 2007, p. 117-118).
\end{abstract}

São oferecidas três concepções antagônicas de Direito (convencionalismo, pragmatismo e direito como integridade), que se diferenciam justamente na descrição da prática jurídica utilizada na etapa pós-interpretativa e sobre quais entendimentos serão extraídos para solucionar os casos difíceis (DIAS, 2015, p. 316).

Quanto ao convencionalismo, é a que apreende o Direito tal como ele é. Seria ele descoberto através de textos e decisões convencionalmente aceitos. Só haveria que se falar em direitos e obrigações se alguma decisão política do passado os tivesse explicitamente reconhecidos. Se, por um lado, o convencionalismo traz segurança jurídica aos destinatários do direito, já que se teria de antemão razões suficientes para o comportamento no seio da comunidade, por outro, é incapaz de solucionar os chamados "casos difíceis", em que inexiste decisão política que explicitamente os regulamente. Falharia o convencionalismo justamente na "continuidade" do romance em cadeia analogicamente tomado por Dworkin para explicar o Direito.

Na etapa pós-interpretativa, o convencionalismo chegaria a duas conclusões:

os juízes devem respeitar as convenções jurídicas em vigor da sua comunidade, a não ser em raras circunstâncias. Insiste, em outras palavras, que ele deve tratar como direito aquilo que a convenção estipula como tal [...] não existe direito - nenhum direito decorrente de decisões tomadas no passado - a não ser aquele que é extraído de tais decisões por meio de técnicas que são, elas próprias, questões de convenção, e que, portanto, em alguns casos não existe direito algum (DWORKIN, 2007, p. 144145),

Ora, em que pese o convencionalismo pregar pela segurança jurídica, em verdade, naqueles casos em que inexistem decisões políticas anteriores, não existiria mesmo o Direito e, portanto, a decisão judicial não estaria "bitolada" por nenhuma decisão política anterior, estando o julgador de certa forma livre para encontrar em suas decisões algum fundamento de uma visão prospectiva. Terá, portanto, o juiz, nos chamados casos difíceis, poder discricionário 
(em sentido forte ${ }^{4}$ ) para criar o Direito e, assim, diante da impossibilidade de negativa da prestação jurisdicional, julgar o caso concreto mesmo inexistente decisão política anterior.

Quanto ao pragmatismo, seria uma concepção cética do Direito ${ }^{5}$. Nela os juízes não estariam comprometidos a qualquer decisão política do passado, tomando suas decisões que lhes pareçam as melhores para o futuro. Não haveria, portanto, que se falar na existência de quaisquer direitos e obrigações subsidiadas em alguma decisão política passada. Permite-se que os juízes desenvolvam livremente o Direito, podendo alterá-lo quando, ao seu critério, entenderem que os benefícios da mudança superem os malefícios da redução da previsibilidade (LOPES, 2015, p. 351) $)^{6}$.

Um ponto ainda merece atenção. No pragmatismo, em que pese inexistir compromisso com as decisões políticas do passado, por razões de estratégia, para se evitar a perda de controle pelo governo, e desta forma canalizar o futuro da comunidade para grau de qualidade inferior, o pragmatismo pode optar por disfarçar a decisão real "simulando" a aplicação da lei (OLIVEIRA, 2016).

Por fim, tem-se a concepção de Direito como integridade, reconhecidamente por Dworkin como a que melhor se ajusta a uma comunidade política.

Na teoria política, Dworkin (2007, p. 200) identifica determinadas virtudes que devem ser consideradas como ideais políticos em comunidade: equidade, como procedimentos políticos que distribuem poder político de forma adequada; justiça, que diz respeito à distribuição pelos legisladores e autoridades de recursos materiais e proteção das liberdades civis; devido processo legal, que diz respeito aos corretos procedimento para julgar o cidadão que violou as normas estabelecidas pelos procedimentos políticos. A integridade, por sua vez, funcionaria como princípio aglutinador das outras virtudes da organização política, ao mesmo

\footnotetext{
4 “O sentido forte do conceito poder discricionário está ligado à autoridade que profere as normas que o juiz deve aplicar aos casos que lhes são apresentados. Quando o juiz não está adstrito aos padrões fixados pela autoridade, dizem os positivistas que ele tem o poder discricionário para decidir do melhor modo que lhe parece" (DIAS, 2019, p. 89).

5 “A tese cética contra a teoria da interpretação de Dworkin consiste no posicionamento de, pelo fato de as pessoas serem diferentes com gostos e valores diferentes com diferentes visões de significados do objeto a ser interpretado, inexistem interpretações certas ou erradas, mas apenas interpretações diferentes" (DIAS, 2015, p. 43).

6 “A diferença prática entre as duas teorias da jurisdição é, portanto, a seguinte: em um regime convencionalista, os juízes não se considerariam livres para alterar regras adotadas conforme as convenções jurídicas correntes, exatamente porque, após o exame de todos os aspectos da questão, uma regra diferente seria mais justa ou eficiente. Em um regime pragmático, nenhuma convenção desse tipo seria reconhecida, e ainda que os juízes normalmente ordenassem o cumprimento de decisões tomadas por outras instituições políticas do passado, eles não reconheceriam nenhum dever legal em fazê-lo" (Dworkin (2007, p. 181).
} 
CHA VES, Carlos Gustavo Chada; DIAS, Jean Carlos. A virada jurisprudencial na exigência de lei complementar para a instituição de tributos: uma abordagem a partir do pensamento de Ronald

tempo em que sinalizaria o caminho a ser seguido no futuro rumo a uma comunidade de princípios a partir de valores reconhecidos no passado ${ }^{7}$.

A moralidade Dworkiniana é a aspiração de se tornar uma "comunidade de princípios, e a imagem que ele cria do sistema jurídico é uma imagem de constante comunicação - de argumentação" (MORRINSON, 2006, p. 520).

\begin{abstract}
Elaboramos nossa terceira concepção do direito, nossa terceira perspectiva sobre quais são os direitos e deveres que decorrem de decisões políticas anteriores, ao reafirmarmos essa orientação como uma tese sobre os fundamentos do direito como integridade, as proposições jurídicas são verdadeiras se constam, ou se derivam, dos princípios de justiça, equidade e devido processo legal que ofereçam a melhor interpretação construtiva da prática jurídica da comunidade (DWORKIN, 2007, p. 272)
\end{abstract}

Fundamental na concepção de Direito como integridade é o conceito de comunidade personificada, dotada de princípios comuns e tomada como um todo que tem obrigações de imparcialidade para com seus membros, devendo as autoridades se comportarem como agentes da comunidade no exercício de suas responsabilidades (FREITAS; COLOMBO, 2017, p. 329).

O princípio do judiciário de integridade instrui os juízes a identificar direitos e deveres legais, até onde for possível, a partir do pressuposto de que foram todos criados por um único autor - a comunidade personificada -, expressando uma concepção coerente de justiça e equidade (DWORKIN, 2007, p. 271-272)

Registre-se novamente que, nesta empresa interpretativa, o juiz, analogicamente concebido como um dos autores do "romance em cadeia", é limitado em ambas as dimensões de adequação, de forma a não ignorar os “capítulos” já escritos, adotando ainda, diante de várias leituras possíveis, aquela melhor interpretação possível da obra (práticas jurídicas), a partir da leitura das virtudes políticas da equidade, justiça e devido processo formal.

A hermenêutica Dworkiniana propõe "uma interpretação geral da prática jurídica, em que o raciocínio jurídico se configure como um exercício de interpretação construtiva que

\footnotetext{
7 "Dworkin treats integrity as a distinctive political value. He initially divides this concept into two parallel notions, corresponding to two different types of legal decision making: integrity in legislation and integrity in adjudication. Integrity in legislation requires the legislature to make the law coherent, bearing in mind a set of overarching values. Integrity in adjudication requires judges to treat the law 'as expressing and respecting a set of coherent principles'. On this view, legal deliberation contains both backward-and forward-looking elements; legal practice is seen as 'an unfolding political narrative. [...] Dworkin's argument for the value of integrity in adjudication takes a similar form. In the first place, it is an argument about the best explanation for judicial practice. For Dworkin, judicial interpretation of legal materials is structured by the notion of intention. The use of intention in legal interpretation, in turn, involves appealing to a set of general goals or principles in order to lend a coherent background context to particular legal rules. This interpretive theory of adjudication is then integrated into an overarching account of legal institutions as reflecting a particular notion of the legal community. It is at this more abstract level that the discrete principles of integrity in legislation and integrity in adjudication yield an overarching notion of law as integrity” (Crowe, 2007, p. 169-170).
} 
incorpora dimensões não consideradas na moldura de uma interpretação semântica" (VIANA, 2015, p 72).

A integridade do Direito é a única, na visão de Dworkin, que possibilitará ao juiz afugentar-se de discricionariedade forte no julgamento de casos difíceis, de forma a encontrar, na própria interpretação da prática jurídica, bases principiológicas/justificativas suficientes para o seu julgamento. Neste sentido, Dias (2015, p. 354-355).

\begin{abstract}
Assim, qualquer juiz pode encontrar-se diante de um caso difícil e a depender de interpretações que deem ao caso, diferentes decisões podem ser tomadas por cada um deles. A sentença e as conclusões, entretanto, sempre deverão advir de uma interpretação de acordo com os fatos anteriores e justificá-los até onde isso seja possível. Sendo assim, a integridade exige que os juízes tratem o Direito como sendo estruturado por princípios de justiça, equidade e o devido processo legal, a fim de que sejam aplicados aos novos casos que surgirem, de forma que a situação seja sempre equitativa e justa
\end{abstract}

Apresentadas as três concepções de direito apresentadas de Dworkin, e destacada a de Direito como integridade como aquela que mais se adequa a uma comunidade de princípios, iremos, nos capítulos seguintes, apresentar três julgamentos históricos prolatados em nível de Supremo Tribunal Federal, para, em seguida, confrontar a jurisprudência objeto do texto, nos termos da concepção adotada por Dworkin.

\title{
2 Jurisprudência analisada
}

No que diz respeito aos acórdãos a serem analisados, tem-se que foram os seguintes critérios de seleção: as decisões do Supremo Tribunal Federal são tomadas em última instância, não cabendo recurso a nenhum outro tribunal brasileiro; os acórdãos escolhidos tiveram grande repercussão no meio acadêmico e na jurisprudência pátria, servindo de paradigma para o estudo em universidades e para outras decisões prolatadas por tribunais inferiores; todas tiveram o mesmo thema decidendum, qual seja a eventual inconstitucionalidade/nulidade de leis locais a quando da inexistência de lei complementar nacional prevendo condições gerais sobre determinada questão, conforme expressa previsão constitucional; houve o transcurso de pequeno intervalo de tempo entre os acórdãos, não havendo alterações significativas nem entre os integrantes da nossa Corte Suprema nem em relação ao material normativo utilizado em suas fundamentações.

A primeira decisão se refere à ADI 2240-7/BA, de relatoria do Ministro Eros Graus, oportunidade em que fora decidido pela inconstitucionalidade da lei baiana $\mathrm{n}^{\circ} 7.619 / 00$. O caso referia-se à compatibilidade ou não da lei que criou o Município de Luis Eduardo Magalhães, 
CHAVES, Carlos Gustavo Chada; DIAS, Jean Carlos. A virada jurisprudencial na exigência de lei complementar para a instituição de tributos: uma abordagem a partir do pensamento de Ronald

Dworkin

decorrente do desmembramento de outros dois distritos, ainda na inexistência de lei complementar federal exigida pelo artigo $18, \S 4^{\circ}$, da $\mathrm{CF} / 88$, que definiria o período em que municípios podem ser criados no País.

Nesta $\mathrm{ADI}^{8}$, no voto que acabou sendo o vencedor, o Ministro Gilmar Mendes, divergindo do relator, Ministro Eros Grau, que votou pela improcedência da ação, ressaltou que, até aquele momento, a Corte Constitucional tinha entendimento de que o art. $18, \S 4^{\circ}$, da $\mathrm{CF} / 88$, tem eficácia limitada, dependendo, portanto, da atuação legislativa no sentido da feitura de lei complementar nele referida para produzir plenos efeitos. Registrou o Eminente Ministro que "ainda que despida de eficácia plena, entende-se que tal norma constitucional tem o condão de inviabilizar a instauração de processos tendentes à criação de novas municipalidades, até o advento da referida lei complementar". Por ter sido criada, portanto, em desconformidade formal ao estabelecido pelo texto constitucional, a lei baiana padecia de vício de nulidade 9 . Por fim, e como forma de equacionar os efeitos práticos da vigência da norma criadora do Município de Luis Eduardo Magalhães, entendeu-se por bem modular os efeitos da decisão declaratória de nulidade por mais vinte e quatro meses, nos termos do art. 27 , da lei $\mathrm{n}^{\circ}$ 9.868/99, tempo suficiente para que o Congresso Nacional editasse a lei complementar exigida pela $\mathrm{CF} / 88$ e que o Estado da Bahia editasse nova lei criadora do município Luis Eduardo Magalhães ${ }^{10}$.

A segunda decisão se refere ao Recurso Extraordinário no 439796/PR, de relatoria do Ministro Joaquim Barbosa. Neste caso, agora referente à matéria tributária (possibilidade de cobrança de ICMS-importação de pessoa física ou jurídica não comerciante habitual do imposto, baseada em lei estadual publicada posteriormente à EC 33/01, mas antes da edição da Lei Complementar Geral 114/02), o posicionamento consolidado na ADI nº 2240-7/BA de inconstitucionalidade e nulidade de leis estaduais ante a inexistência de LC nacional geral exigida pela Constituição Federal fora ratificado por nossa Corte Suprema ${ }^{11}$.

\footnotetext{
${ }^{8}$ Disponível em: http://redir.stf.jus.br/paginadorpub/paginador.jsp?docTP=AC\&docID=474616.

${ }^{9}$ O posicionamento da Suprema Corte quanto à inconstitucionalidade e conseguinte nulidade de criação de município por lei estadual sem respaldo de lei complementar nacional foi ratificado, dentre outros, nos seguintes julgamentos: ADI-MC no 2.381/RS, ADI n 3.149/SC, ADI nº 2.702/PR.

${ }^{10}$ A necessidade de edição de nova lei local de criação do município se daria em razão de ser vedado no sistema jurídico brasileiro o fenômeno da constitucionalização superveniente, que ocorre quando uma lei originalmente incompatível com o texto constitucional até então vigente vem a se tornar compatível com modificações posteriores introduzidas na Constituição por meio do exercício do Poder Constituinte Reformador ou eventualmente pela vigência de nova Constituição.

${ }^{11} \mathrm{O}$ mesmo posicionamento quanto à inconstitucionalidade de ICMS-importação por pessoa física através de lei estadual sem respaldo em lei complementar nacional anterior foi ratificado, dentre outros, nos seguintes julgamentos: RE no 474.267/RS - STF e AP nº 0016509-42.2016.8.19.0001 TJRJ.
} 
CHAVES, Carlos Gustavo Chada; DIAS, Jean Carlos. A virada jurisprudenciall na exigência de lei complementar para a instituição de tributos: uma abordagem a partir do pensamento de Ronald

Dworkin

No voto vencedor de lavra do Ministro Joaquim Barbosa, reconhecida a inovação trazida pela $\mathrm{EC} \mathrm{n}^{\circ} 33 / 01$, no sentido de inaugurar competência dos Estados para a cobrança de ICM-importação de bens e mercadorias por pessoas físicas ou jurídicas não comerciantes habituais do imposto e a conseguinte superação da súmula $\mathrm{n}^{\circ} 660$, do $\mathrm{STF}^{12}$, restou fixado mais uma vez que é condição de validade (não de eficácia) das normas locais a existência prévia, quando exigido constitucionalmente, a edição de lei complementar nacional fixando seus termos gerais. Restou também ratificado o entendimento da impossibilidade no sistema jurídico brasileiro do fenômeno chamado "constitucionalidade superveniente", que ocorre quando uma lei viola texto constitucional, vindo, todavia, a adequar-se a ele após a reforma da Constituição. O entendimento firmado pela Suprema Corte pode ser resumido no trecho do voto do Eminente Ministro Joaquim Barbosa

Senhores Ministros, lembro que interrompemos este julgamento logo após a prolação do voto do Ministro Dias Toffoli, na sessão de 16.12.2010. Nesses dois recursos extraordinários, discute-se se as pessoas jurídicas que não sejam comerciantes podem ser sujeitos passivos do ICMS, incidente nas operações de importação, especialmente após a superveniência da EC 33/2001. Em síntese, expus que nenhuma das três restrições observadas pela Corte no julgamento dos precedentes relacionados ao tema, firmados antes da EC 33/2000, continuavam aplicáveis. Afirmei que a caracterização de "bem" como "mercadoria" independia da qualidade jurídica do adquirente. Apontei a inexistência de cumulatividade a ser equilibrada com a compensação, na medida em que existente apenas uma única operação. Por fim, com a alteração realizada no texto constitucional em 2000, a falta do critério para definição do sujeito ativo foi suprida com a inserção da palavra "domicílio" no art. $155, \S 2^{\circ}, X$, a da Constituição. A posição externada pelo Ministro Dias Toffoli na sessão em que proferido o voto-vista de Sua Excelência coincide quase integralmente com os parâmetros traçados em meu próprio voto. A divergência ficou por conta da possibilidade de exame, nesses recursos extraordinários, da suficiência da legislação infraconstitucional para dar densidade às normas gerais em matéria tributária e à própria regra-matriz do tributo. Com apoio na Súmula 456/STF e para impedir que o tema se prolongue no Judiciário, entendo possível ampliar o campo de cognição do recurso para alcançar o debate sobre a densificação da competência tributária. A fundamentação é bastante simples, se tivermos cuidado para segmentar cada uma das etapas do fluxo de positivação da regra-matriz. De acordo com a jurisprudência desta Suprema Corte, a existência de competência tributária é insuficiente para justificar a cobrança do tributo, isto é, a constituição do crédito tributário. A competência deve ser exercida por agente competente e segundo o procedimento legislativo previsto. Essa orientação vem desde a antiga discussão sobre a incidência do ICM no fornecimento de alimentos e bebidas por restaurantes e congêneres (Súmula 574/STF). Porém, a instituição da regra-matriz é isoladamente insuficiente. A própria norma que institui o tributo deve encontrar fundamento de validade nas normas gerais, imprescindíveis para o ICMS, para assegurar estabilidade e previsibilidade em nosso país, em cujo Estado a competência tributária é partilhada com 26 estados, o Distrito Federal e mais de 5.500 municípios (arts. 24, $\S \S 3^{\circ}$ e $4^{\circ}$ e 155 , XII, a, d e i da Constituição). Para que a constituição do crédito tributário seja válida, a incidência deve ocorrer na presença concomitante dessas três condicionantes: existência de competência, exercício dessa competência pela União, resultante em norma geral em matéria tributária e exercício de competência por cada um dos estados-membros e pelo Distrito Federal, resultante na regra-matriz de

\footnotetext{
${ }^{12}$ Não incide ICMS na importação de bens por pessoa física ou jurídica que não seja contribuinte do imposto.
} 
incidência tributária. Ocorre que alguns entes federados se precipitaram, ora à EC 33/2001, ora à lei complementar de normas gerais, e acabaram criando regrasmatrizes sem o necessário fundamento de validade. Nesses casos, entendo aplicável a orientação firmada por esta Suprema Corte no RE 346.084 e no RE 390.840, que afasta o fenômeno da "constitucionalização superveniente" de nosso sistema jurídico. Para ser constitucionalmente válida a incidência do ICMS sobre operações de importação de bens, irrelevante a qualificação jurídica do adquirente, as modificações no critério material, na base de cálculo e no sujeito passivo da regra-matriz devem ter sido realizadas em lei posterior à $\mathrm{EC} \mathrm{33/2001}$ e à LC 114/2002 (que modificou a LC 87/1996, para prever normas gerais específicas à incidência sobre importação de bens, independentemente de se tratar de adquirente-comerciante). (STF - RE: 439796 PR, Relator: Min. JOAQUIM BARBOSA, Data de Julgamento: 06/11/2013, Tribunal Pleno, Data de Publicação: ACÓRDÃO ELETRÔNICO DJe-051 DIVULG 14-03-2014 PUBLIC 17-03-2014). Grifou-se.

A terceira decisão se refere ao Ag. Reg Rec. Extr. 917.950/SP, de relatoria do Ministro Teori Zavascki, em que nossa Corte Suprema, analisando agora a constitucionalidade de lei paulista autorizadora de ICMS-importação de pessoa física ou jurídica não comerciante habitual do imposto, publicada anteriormente à LC 114/02, alterando o posicionamento até então consolidado, entendeu que a inexistência de Lei Complementar Nacional geral exigida por dispositivo expresso pela Constituição não geraria a automática nulidade/invalidade de lei local e, por conseguinte, da cobrança do ICMS-importação durante toda a sua vigência, sendo a sua publicação (da lei complementar) apenas condição de eficácia.

O entendimento firmado pode ser melhor resumido no trecho do voto vencedor do Ministro Gilmar Mendes

Não se pode punir com a pecha de inconstitucional o ato do ente federativo diligente que, amparado por autorização constitucional e no exercício de sua competência tributária, alterou seu arcabouço normativo estadual para expressar o exato contido naquela norma. $\mathbf{E}$ bem verdade que a efetividade desse poder tributante dependeria de lei complementar federal, todavia não seria caso de inconstitucionalidade formal ou material, mas, tão somente, de condição de eficácia daquele exercício após a superveniência da legislação necessária. Caso contrário, exemplificadamente no Estado de São Paulo, chegaríamos a situação na qual, em razão de até hoje não ter havido alteração normativa quanto ao contribuinte do ICMS-importação após a Lei Complementar Federal 114/02, o referido Ente Federativo estaria impedido de cobrar o aludido tributo. Pensando consequencialmente, daríamos azo a incontáveis ações de repetição de indébitos, a promover desfalque ainda maior nas combalidas receitas estaduais. Portanto, penso que, conjugando a linha do precedente da Corte, deve-se compreender que as leis anteriores à Lei Complementar 114/02 e posteriores à EC33/01 não são inconstitucionais. A questão resolve-se no plano da eficácia. Vale dizer, no período após a EC e anterior à Lei Complementar Federal, não haveria inconstitucionalidade, mas tão só ineficácia da legislação estadual até 17.12.2002 (vigência da Lei Complementar 114/02), de sorte que seriam insubsistentes créditos tributários advindos de fatos geradores anteriores a tal marco. Em outras palavras, apenas a partir da edição da Lei Complementar 114/02, observado o princípio da anteridade nonagesimal, é que estados estão autorizados a realizar a cobrança de ICMS-importação, nos termos da Emenda Constitucional 33/01. Preserva-se, portanto, a validade das leis estaduais editadas após a referida emenda. (RE 917950 AgR, Relator(a): Min. TEORI ZAVASCKI, Relator(a) p/ 
CHA VES, Carlos Gustavo Chada; DIAS, Jean Carlos. A viradla jurisprudencial na exigência de lei complementar para a instituição de tributos: uma abordagem a partir do pensamento de Ronald

Dworkin

Acórdão: Min. GILMAR MENDES, Segunda Turma, julgado em 05/12/2017, ACÓRDÃO ELETRÔNICO DJe-114 DIVULG 08-06-2018 PUBLIC 11-06-2018)

Registre-se que, durante os debates do Ag. Reg Rec. Extr. 917.950/SP, tanto o Ministro Gilmar Mendes quanto o Ministro Dias Toffoli fizeram questão de salientar que o caso que estava sendo analisado seria diferente daquele julgado no RE $n^{\circ} 439796$ PR, ressaltando que não teria ficado claro se a legislação superveniente à emenda constitucional 33/01, mas anterior à Lei Complementar Federal no 114/02, estaria fadada de algum vício de inconstitucionalidade material ou formal. Ressaltou-se ainda que, por se encontrar a publicação de exigida lei complementar nacional apenas no plano de eficácia da legislação local (e não de validade), afastada também estaria ao caso a hipótese de "constitucionalidade superveniente" ou convalidação de lei anterior”.

Neste sentido, extrai-se trecho do voto do Ministro Dias Toffoli

\begin{abstract}
Entendo que, realmente, a questão se resolve no plano da eficácia e não no da declaração de inconstitucionalidade da lei estadual editada em conformidade com a $\mathrm{EC} \mathrm{n}^{\mathrm{o}} 33 / 2001$ antes da lei complementar de normas gerais exigida pelo art. 155, XII, da Constituição. Com o advento da EC n⿳ 33/2001, surgiram, no texto constitucional, novos contribuintes de direito do ICMS-importação (além de novo fato gerador do

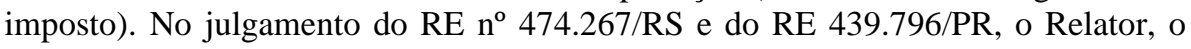
Ministro Joaquim Barbosa, levando em consideração especialmente o art. 155, XII, i, da Constituição, sustentou que seria necessária para a exigência válida do imposto a existência da previsão constitucional ( $E C n^{\circ} 33 / 2001$ ), de norma geral editada pela União (LC no 114/2002) e de lei em cada estado ou no Distrito Federal com a regra matriz de incidência. Nesse julgado, de fato, não ficou claro se a

legislação superveniente à Emenda Constitucional 33/2001 anterior à Lei Complementar Federal 114/2002 padeceria de algum vício de inconstitucionalidade [...]Assim, no Estado de São Paulo, é constitucional a Lei n ${ }^{\circ} 11.001 / 2001$, por ter sido editada quando já vigente o dispositivo constitucional que autoriza a incidência do ICMS na hipótese. Não se trata de caso de "constitucionalidade superveniente" ou de "convalidação de lei anterior", pois a Lei estadual no 11.001/2001 nunca foi inconstitucional. (RE 917950 AgR, Relator(a): Min. TEORI ZAVASCKI, Relator(a) p/ Acórdão: Min. GILMAR MENDES, Segunda Turma, julgado em 05/12/2017, ACÓRDÃO ELETRÔNICO DJe-114 DIVULG 08-06-2018 PUBLIC 11-06-2018)
\end{abstract}

Em que pese a insistência dos Ministros da Corte Suprema em tentar diferenciar aquilo que estava sendo decidido no Ag. Reg Rec. Extr. 917.950/SP do que restou assentado no RExt 439796 PR, fato é que inexistiu qualquer assimetria. Bastaria uma breve consulta ao voto do Ministro Relator deste último julgamento (trecho mencionado acima) para se constatar que se fixou que a pecha de invalidade reconhecida em ratio decidendi abarcou não apenas as leis locais editadas anteriormente à $\mathrm{EC} \mathrm{n}^{\mathbf{0}} 33 / 01$ como também aquelas editadas posteriormente à reforma constitucional, mas anteriormente à $L C \mathrm{n}^{\circ}$ 114/02. Da mesma forma, foi o Ministro Relator categórico no sentido de que, eivadas as leis locais anteriores à LC 114/02, impossível 
CHA VES, Carlos Gustavo Chada; DIAS, Jean Carlos. A virada jurisprudencial na exigência de lei complementar para a instituição de tributos: uma abordagem a partir do pensamento de Ronald

a sua ratificação posterior, em razão da vedação de inexistir em nosso sistema jurídico o fenômeno da constitucionalidade superveniente.

De toda a forma, mesmo se existisse a diferença alegada pelos ministros Gilmar Mendes e Dias Toffoli, também é fato que a Suprema Corte já havia firmado, pelo menos desde o julgamento na ADI 2240-7/BA, de que inexistência de lei complementar geral prévia exigida constitucionalmente é requisito para a validade da legislação local, de forma que, se não obedecido, eiva-a de nulidade, não podendo ser posteriormente convalidada, por não ser aceito no Brasil o chamado fenômeno da "constitucionalidade superveniente".

Pois, então, do breve contato com a mudança jurisprudencial firmada no Ag. Reg Rec. Extr. 917.950 SP, e a partir das breves explanações iniciais, extrai-se as seguintes indagações que se tentará responder no capítulo seguinte: será que a mudança de entendimento de nossa Corte Suprema quanto à (in)validade das leis estaduais questionadas pode ser considerada como uma ofensa à virtude política da justiça, defendida por Dworkin? Será que no acórdão referente ao Ag. Reg Rec. Extr. 917.950 SP houve respeito por parte de nossa Corte Suprema à dimensão da adequação da prática jurídica estabelecida quanto ao tema da inconstitucionalidade das leis estaduais publicadas sem respaldo em LC nacional? Enfim, ao estabelecer verdadeira guinada jurisprudencial, houve por parte de nossa Corte Suprema respeito à concepção Dworkiniana de direito como integridade ou se pode falar mais em um pragmatismo do STF? Essas são as perguntas que serão respondidas no capítulo seguinte.

\section{3 (In)compatibilidade da jurisprudência do STF firmada no Ag. Reg. Rec. Extr. 917.950/SP à luz da concepção de Direito como integridade}

Conforme explanado nos capítulos anteriores, Dworkin desenvolveu, em especial para os chamados casos difíceis, uma concepção de Direito que pressupõe a existência de direitos e deveres morais não relatados expressamente em modelos normativos estabelecidos. Tais direitos e obrigações são estabelecidos por princípios que têm basicamente duas funções: são elementos para a identificação de resposta correta; impedem a discricionariedade judicial. Fora mencionado também que os princípios jurídicos são extraídos a partir de uma moralidade da comunidade política, vista essa como ente autônomo, dotada de determinadas virtudes (equidade, devido processo formal, justiça e integridade).

Para Dworkin, os princípios são extraídos a partir da interpretação da prática jurídica de determinada comunidade, em um modelo equiparado a um "romance em cadeia", em que o julgador é tido ao mesmo tempo como intérprete dos capítulos já escritos como também coautor dos capítulos a serem continuamente escritos. (MORKING; VIEIRA JÚNIOR, 2015, p. 202). 
CHAVES, Carlos Gustavo Chada; DIAS, Jean Carlos. A virada jurisprudencial na exigência de lei complementar para a instituição de tributos: uma abordagem a partir do pensamento de Ronald

Dworkin

Por fim, tem-se que os intérpretes do Direito apresentam discordâncias relevantes, dentro do modelo de interpretação proposto, na etapa pós-interpretativa, tendo Dworkin entendido o de integridade como o que melhor se apresenta para se extrair os melhores princípios da prática judicial de determinada comunidade política e que servirão de guia para o reconhecimento de direitos e obrigações não pré-estabelecidos expressamente por normas. (MORKING; VIEIRA JÚNIOR, 2015, p. 202).

No que diz respeito aos entendimentos firmados nos acórdãos acima referidos, nossa Corte Suprema, ao analisar tal incompatibilidade constitucional, nos dois primeiros acórdãos citados estabeleceu como princípio regulador o de que a não edição de lei complementar exigida pela Constituição Federal para a fixação de normas gerais sobre determinado assunto impede que o legislador local edite lei ordinária reguladora. A edição de lei complementar nacional funcionaria assim como uma condicionante constitucional ao pleno exercício do poder legislativo local, sendo que a eventualidade de publicação de lei estadual, na situação de ainda inexistência de lei complementar, acarretaria ofensa direta à Constituição, sendo, por este motivo, inconstitucional e nula de pleno direito.

Tal entendimento da Corte Suprema até então firmado, de certa forma, vem ao encontro de posicionamento que há muito se observa da prática judicial brasileira. Adota-se, no Brasil o princípio de que toda a legislação infraconstitucional deve, por obediência hierárquica, ser compatível formal e materialmente às normas e princípios estabelecidos na Constituição Federal, sob pena de eiva de invalidade constitucional e, por consequência, de nulidade. Não há anulação da lei inconstitucional. Ela é nula de pleno direito. Já nasce viciada de doença mortal invencível, não podendo, portanto, de nenhuma forma, ser posteriormente convalidada. É o que se denomina princípio da nulidade da lei inconstitucional ${ }^{13}$.

Nos dois primeiros acórdãos apresentados, portanto, nossa Suprema Corte nada mais fez do que interpretar a prática judicial brasileira no sentido de que eventuais incompatibilidades de leis infraconstitucionais com a Constituição Federal as eivariam de nulidade, de nenhum efeito, portanto, alijando-as do ordenamento jurídico brasileiro. Afinal,

\footnotetext{
13 “O dogma da nulidade da lei inconstitucional pertence à tradição do direito brasileiro. A teoria da nulidade tem sido sustentada por praticamente todos os nossos importantes constitucionalistas. Fundada na antiga doutrina americana, segundo a qual "the inconstitutional statute is not law at all", significativa parcela da doutrina brasileira posicionou-se em favor da equiparação entre inconstitucionalidade e nulidade. Afirmava-se, em favor dessa tese, que o reconhecimento de qualquer efeito a uma lei inconstitucional importaria na suspensão provisória ou parcial da Constituição [...] Uma alteração posterior do Regimento Interno do Supremo Tribunal Federal deixou assente que, apenas na hipótese de decisão proferida no controle incidental de normas (art. 178), estava a Corte obrigada a informar o Senado Federal sobre a declaração de inconstitucionalidade" (MENDES, 1995, p. 283-297).
} 
este é o entendimento consolidado como princípio na prática judicial brasileira, não existindo nada, pelo menos nos dois acórdãos abordados (e no restante da jurisprudência e doutrinas unânime), que indicasse possibilidade de mudança de entendimento.

A decisão apresentada no terceiro acórdão representou uma mudança de entendimento

até então seguido por toda a jurisprudência nacional, em especial do STF, particularizando caso de expresso descompasso entre lei estadual e a Constituição Federal, afastando a sua nulidade, tal como remansoso até então, para considerar sua validade, cuja apenas a eficácia estaria condicionada à edição de lei complementar posterior $^{14}$.

Pergunta-se novamente: será que houve respeito por parte de nossa Corte Suprema à dimensão da adequação da prática jurídica? Esta guinada jurisprudencial pode ser considerada como uma ofensa à virtude política da justiça, defendida por Dworkin? Enfim, houve por parte de nossa Corte Suprema respeito à concepção Dworkiniana de Direito como integridade ou seria típico caso de pragmatismo jurídico?

No que diz respeito à primeira indagação, conforme já fora adiantado, o Direito como integridade na interpretação das práticas jurídicas exige que o julgador, dentro de sua postura de coautor do romance em cadeia, adeque-se aos princípios extraídos da prática judicial existente no seio de determinada comunidade política. A liberdade criativa não é plena, mas restringida por aquilo que já fora escrito nos capítulos anteriores. Não se trata de um recomeço, de um restart, mas sim de interpretação possível daquilo que já fora escrito e continuidade desta empresa interpretativa interminável.

O entendimento firmado e consolidado da prática jurídica nacional é da vigência de principio de nulidade de legislação infraconstitucional a quando de sua incompatibilidade (material e formal) com a Constituição Federal. Não há divergência jurisprudencial ou doutrinária quanto a este ponto. A supremacia da Carta Magna e a proteção de direitos nela previstos são garantidas não apenas com a compatibilidade dos atos de particulares e de agentes públicos aos seus ditames como também pela compatibilidade hierárquica de toda a normatividade de grau inferior. Evita-se assim que decisões políticas tomadas pela maioria dos membros de determinada comunidade específica venham a solapar direitos constitucionalmente reconhecidos explícita e/ou implicitamente em âmbito constitucional. É por este motivo, portanto, que qualquer decisão política, por melhores que sejam suas intenções, deve se compatibilizar com os ditames da Carta Magna, sob pena de ser considerada nula de pleno direito.

\footnotetext{
${ }^{14} \mathrm{Na}$ denominada "escada ponteana", a incompatibilidade constitucional da lei local fora deslocada do degrau de validade para o degrau de ineficácia.
} 
CHA VES, Carlos Gustavo Chada; DIAS, Jean Carlos. A virada jurisprudencial na exigência de lei complementar para a instituição de tributos: uma abordagem a partir do pensamento de Ronald

Dworkin

Desta forma e, portanto, ao ignorar a prática judicial em nossa comunidade política para caso específico de inconstitucionalidade formal, tem-se que o Supremo Tribunal Federal desrespeitou em seu empreendimento interpretativo a dimensão da adequação ao "romance em cadeia" até então construído. O STF inovou e reconstruiu a prática jurídica em verdadeiro descompromisso com todas as virtudes da comunidade política reconhecidas por Dworkin.

No que diz respeito à segunda pergunta, vale lembrar que Dworkin identifica a virtude da justiça como a que diz respeito à distribuição pelos legisladores e autoridades de recursos materiais e proteção das liberdades civis. Os bens da comunidade política, para bem servir aos ditames de justiça, devem ser distribuídos aos seus integrantes de forma equânime, não havendo lugar para diferenciações injustificáveis. Uma comunidade é justa somente se trata seus membros de maneira igual, sendo as diferenças apenas possíveis se justos forem os seus objetivos.

Ao individualizar o Supremo Tribunal Federal um caso específico de inconstitucionalidade, afastando a nulidade da lei, tem-se que ofendeu a virtude de justiça da comunidade política. Não existem particularidades na inconstitucionalidade da lei paulista que justifiquem principiologicamente tratamento específico, destoem da prática judicial e afastem sua eiva de nulidade. Isto, aliás, sequer foi mencionado nos votos vencedores. $\mathrm{O}$ descompromisso com justiça é ainda mais grave quando lembramos que leis anteriores mencionadas acima, eivadas da mesma incompatibilidade constitucional, e de relevância social muito superior, como no caso de criação de municípios, foram alijadas do sistema jurídico pelo mesmo tribunal (houve apenas protelação da eficácia da decisão de nulidade). A proteção de contribuintes brasileiros diante da ganância tributária de seus Estados foi tratada pela Suprema Corte de maneira injusta e bastante diferente, dando a entender que as pessoas residentes no Estado de São Paulo, pela simples razão de aí residirem, merecem proteção constitucional absolutamente diferente e inferior a dos residentes do Estado do Paraná e de outros Estados da Federação. Houve manifesto pragmatismo jurídico da Suprema Corte. Ignorou-se histórica tradição judicial com o claro fito de manter-se o equilíbrio fiscal do Estado Paulista, o que inclusive foi ressaltado no voto do Ministro Gilmar Mendes, ao mostrar-se claramente preocupado com a eventual "avalanche" de ações de repetição de indébito que seriam propostas no caso de ser reconhecida a inconstitucionalidade da lei autorizativa de cobrança de ICMSimportação.

Por fim, em relação à ultima indagação, forçoso é o reconhecimento da incompatibilidade da jurisprudência firmada no Ag. Reg. Rec. Extr. 917.950/SP com a concepção de Direito como integridade. A integridade do Direito consiste em processo 
CHA VES, Carlos Gustavo Chada; DIAS, Jean Carlos. A virada jurisprudencial na exigência de lei complementar para a instituição de tributos: uma abordagem a partir do pensamento de Ronald

interpretativo da prática jurídica formada não apenas de regras expressas, mas de princípios identificados a partir das próprias virtudes políticas da comunidade política. No caso, identificado o princípio da nulidade das leis inconstitucionais como a mais adequada à luz dos principais objetivos e valores da prática jurídica, é incompatível com a integridade do Direito a sua relativização a caso específico de inconstitucionalidade. Age em verdadeiro descompromisso com as virtudes políticas que se espera de uma Corte Constitucional, quando ignora, sem justificativa, princípios consolidados e decorrentes da prática judicial e necessários à garantia da proteção aos membros da comunidade política.

Ao que parece, em que pese isto não ter sido mencionado no texto da ementa, a decisão da nossa Corte Suprema fora baseada muito mais em justificativa de política do que de princípio. É instintivo se pensar que o enquadramento de incompatibilidade constitucional para nível de ineficácia da lei teve muito mais razões de política de equilíbrio fiscal do Estado de São Paulo do que do que sendo fruto mesmo de interpretação virtuosa de nossa prática jurídica. Trata-se de verdadeiro pragmatismo jurídico (objetiva-se manter o equilíbrio fiscal, evitandose inúmeras ações de repetição de indébito tributário) absolutamente incompatível com a concepção Dworkiniana de direito como integridade.

\section{Considerações finais}

O presente artigo teve como finalidade inicial apresentar o conceito Dworkiniano do Direito como processo interpretativo da pratica judicial em evolução. O Direito seria assim formado não apenas de regras decorrentes de escolha política, como também de princípios extraídos da prática judicial.

Apresentou-se, em seguida, três etapas seguidas pelo intérprete do Direito denominadas pré-interpretativa, interpretativas e pós-interpretativas. Dworkin explana que há basicamente um consenso entre as duas primeiras fases do processo interpretativo, sendo a divergência notada mesmo na última fase. Para tanto, fora apresentada a concepção Dworkiniana do Direito como integridade, afastando-se do convencionalismo e pragmatismo, como aquela mais adequada à identificação dos princípios extraíveis de determinada prática judicial que justificam a existência de direitos e deveres dos membros da comunidade e justificam também, ao lado das decisões políticas, a coerção estatal.

Apresentadas as ideias básicas da concepção de Direito como integridade, foram apresentados três acórdãos em que a Suprema Corte apreciou a questão de eventual 
CHAVES, Carlos Gustavo Chada; DIAS, Jean Carlos. A virada jurisprudencial na exigência de lei complementar para a instituição de tributos: uma abordagem a partir do pensamento de Ronald

inconstitucionalidade de lei estadual, diante de inexistência de lei complementar geral expressamente exigida pela Constituição Federal

Por fim, fora defendido que a guinada jurisprudencial firmada no Ag. Reg. Rec. Ext. $n^{\circ}$ 917.950/SP, reconhecendo apenas a ineficácia da lei paulista $\mathrm{n}^{\circ}$ 11.001/2001 (e não sua nulidade, como historicamente vinha-se reconhecendo em hipóteses semelhantes), mesmo tendo sido editada anteriormente à Lei Complementar Geral 114/02, viola a concepção Dworkiniana de Direito como integridade, estando pautada, em que pese isso não se encontrar expresso, apenas em justificativas políticas de equilíbrio fiscal do Estado de São Paulo (puro pragmatismo jurídico), e não em justificativas de princípios extraídos da prática judicial da comunidade.

Pode-se dizer assim que agiu em verdadeira má-fé, segundo Dworkin, nossa Corte Suprema, quando em descompromisso para com a história política de nossa comunidade, passou a defender em caso isolado de inconstitucionalidade formal de lei estadual, não a sua nulidade, mas apenas a sua ineficácia. Fez política disfarçada de julgamento, em total desacerto em suas funções constitucionais. Ao fim e ao cabo, em verdadeiro pragmatismo, e em discordância da sua história institucional, atuou unicamente como trincheira das contas públicas do Estado de São Paulo, em verdadeiro descompromisso institucional de protetor da hierarquia da Constituição e dos direitos e garantias nela previstos.

\section{Referências}

BRASIL. Supemo Tribunal Federal. Ação direta de inconstitucionalidade: Adi 2240/BA. Relator: Ministro Eros Grau. Diário da Justiça: 09/05/2007. JusBrasil. 2007. Disponível em: https://stf.jusbrasil.com.br/jurisprudencia/757312/acao-direta-de-inconstitucionalidade-adi-22 40-ba. Acesso em: 05 de jul. 2019.

BRASIL. Superior Tribunal Federal. Recurso Extraordinário: 439796/PR. Relator: Ministro Joaquim Barbosa. DJ: 06.11.2013. JusBrasil. 2013. Disponível em: https://stf.jusbrasil.com.br/jurisprudencia/25136159/recurso-extraordinario-re-439796-pr-stf/ inteiro-teor-124551311. Acesso em: 05 de jul. de 2019.

BRASIL. Supremo Tribunal Federal. Agravo Regimental Em Recurso Extraordinário: Re 917950 AgR/ SP. Relator: Ministro Teori Zavascki. Relator para acórdão: Ministro Gilmar Mendes. Diário da Justiça: 05.12.2017. 2017. Disponível em: http://www.stf.jus.br/portal/jurisprudencia/listarJurisprudencia.asp?s1=\%28917950\%2ENUM $\mathrm{E} \% 2 \mathrm{E}+\mathrm{OU}+917950 \% 2 \mathrm{EACMS} \% 2 \mathrm{E} \% 29 \&$ base=baseAcordaos\&url=http://tinyurl.com/yxnfy 2pn. Acesso em: 05 de jul. de 2019.

CHRISTIE, George. Dworkin's empire. Duke Law Journal. 7th ed. Chicago, 157-190. 1987. HeinOnline. 
CROWE, Jonathan. Dworkin on the Value of Integrity. Deakin Law Review, vol. 12, n. 1, p. 167-180, 2007. HeinOnline.

DIAS, Jean Carlos. O pensamento jurídico contemporâneo. Rio de Janeiro: Método, 2015.

DIAS, Jean Carlos. Teorias contemporaneas do direito e da justiça. Salvador: Juspodivm, 2019.

DORKIN, Eric. Debunking Integrity's "Equality Advantage": The Absence of Coordination in Ronald Dworkin's Law's Empire". Iowa Law Review, Iowa, v. 83, n. 5, p. 1071-1114, 1998. HeinOnline.

DWORKIN, Ronald. O império do direito. 2. ed. São Paulo: Martins Fontes, 2007.

DWORKIN, Ronald. Uma questão de princípio. 2. ed. São Paulo: Martins Fontes, 2001.

FREITAS, Vladimir Passos de; COLOMBO, Silvana Raquel Brendler. A dimensão interpretativa do direito como integridade a partir de Ronald Dworkin. Direito e Liberdade, Natal, v. 19, n. 1, p. 321-349, jan./abr. 2017.

LOPES, Priscila Silva. Teoria argumentativa de Dworkin do direito como integridade. In: DIAS, J. C. (org.). O pensamento jurídico contemporâneo. São Paulo: Método, 2015. p. 343-360.

MACEDO JÚNIOR, Ronaldo Porto. Do xadrez à cortesia. São Paulo: Saraiva, 2013.

MENDES, Gilmar Ferreira. A nulidade da lei inconstitucional e seus efeitos. Revista da Faculdade de Direito Universidade Federal de Minas Gerais, Belo Horizonte, n. 35, 1995.

MORKING, Francelize Alves; VIEIRA JÚNIOR, Dicésar Beches;. Ronald Dworkin e o direito como integridade: uma teoria da decisão judicial aplicada ao direito do trabalho. Paradigma, Ribeirão Preto, v. 24, n. 1, p. 186-212, jan./jun. 2015. Disponível em: https://revistas.unaerp.br/paradigma/article/view/476. Acesso em: 16 dez. 2021.

MORRINSON, Wayne. Filosofia do direito: dos gregos ao pós modernismo. São Paulo: Martins Fontes, 2006.

OLIVEIRA, Márcio Etiane Nogueira Almendros de. Dworkin e o direito como integridade. 2016. Trabalho de conclusão de curso (Especialização em Teoria e Filosofia do Direito) Pontifícia Universidade Católica de Minas Gerais, Belo Horizonte, 2016.

SADOWSKI, Marianne. Language Is Not Life: The Chain Enterprise, Interpretive Communities, and the Dworkin/Fish Debate. Connecticut Law Review, Connecticut, v. 33, n. 3, 2001, p. 1099-1140. HeinOnline.

SNOWDEN, John Rockwell. The Justification Story: Law as Integrity and Deviationist Doctrine. Journal of Law and Religion, v. 9, ed. 1, p. 49-88, 1991. HeinOnline.

VIANA, Lorena Mesquita Silva. A dignidade da pessoa humana e a jurisprudência do Supremo Tribunal Federal: uma abordagem crítica à luz da teoria do direito como 
CHA VES, Carlos Gustavo Chada; DIAS, Jean Carlos. A virada jurisprudenciall na exigência de lei complementar para a instituição de tributos: uma abordagem a partir do pensamento de Ronald

integridade de Ronald Dworkin. Tese (Mestrado em Direito, Políticas Públicas e Desenvolvimento Regional) - Programa de pós-graduação stricto sensu em Direito, Centro Universitário do Estado do Pará, Belém, 2015. 